\title{
High prevalence of bronchial hyperresponsiveness and asthma in ice hockey players
}

\author{
J.D. Leuppi*, M. Kuhn*, C. Comminot+, W.H. Reinhart*
}

\begin{abstract}
High prevalence of bronchial hyperresponsiveness and asthma in ice hockey players. J.D. Leuppi, M. Kuhn, C. Comminot, W.H. Reinhart. (CERS Journals Ltd 1998.

ABSTRACT: The prevalence of asthma was studied in a ice hockey team compared with both a floor ball team and the Swiss population.

Lung function, bronchial hyperresponsiveness to methacholine, asthma symptoms and exercise-induced asthma were measured in a cross-sectional prospective study.

A positive response to the methacholine bronchial provocation test was found in $34.6 \%$ of the ice hockey players and $20.8 \%$ of the floor ball players (Swiss population $16.4 \%$ ). The provocative dose causing a $20 \%$ fall in the forced expiratory volume in one second (PD20) was significantly lower in ice hockey players than in floor ball players, but there was no significant difference in the dose-response slopes between the two groups. Asthma was diagnosed in $19.2 \%$ of the ice hockey players and in $4.2 \%$ of the floor ball players (Swiss population $6.8 \%$ ), whereas exercise-induced asthma was found in $11.5 \%$ of the ice hockey players and in $4.2 \%$ of the floor ball players.

In conclusion, asthma and bronchial hyperresponsiveness seemed to be more common in ice hockey players than in floor ball players and in the Swiss population. Strenuous exercise at lower temperatures may be a risk factor for the higher prevalence of asthma and bronchial hyperresponsiveness, as well as the increased severity of bronchial hyperresponsiveness, particularly in ice hockey players. Eur Respir J 1998; 12: 13-16.
\end{abstract} \author{
Switzerland. \\ Correspondence: M. Kuhn \\ Dept of Internal Medicine \\ Kantonsspital \\ CH-7000 Chur \\ Switzerland \\ Fax: 41812566379
}

*Dept of Internal Medicine, Kantonsspital, Chur, Switzerland. +Team Physician, Chur,

\section{Keywords: Asthma}

bronchial hyperresponsiveness

floor ball

ice hockey

\section{Received: July 111997}

Accepted after revision March 151998

Supported by Bündner Liga für Lungenkrankheiten und Tuberkulose and the Wilhelm Doerenkamp Foundation.
Asthma and exercise-induced asthma are not uncommon in either the general population or trained athletes [1]. A prevalence of $16.4 \%$ for bronchial hyperresponsiveness [2] and of $6.8 \%$ for asthma was found for the general Swiss population in the Swiss study on air pollution and lung diseases in adults (SAPALDIA study) [3]. The prevalence of exercise-induced asthma in Swiss athletes was estimated to be $4.25 \%$ [4]. In 1993 LARSSon et al. [5] reported a high prevalence of asthma in Swedish cross-country skiers. This sport is performed at low temperatures, often below $-10^{\circ} \mathrm{C}$. The pathophysiological mechanism responsible for exercise-induced asthma is probably evaporative water loss from the airway mucosa [6] leading to irritation by local airway hyperosmolarity. Inhaling large amounts of cold air triggers bronchoconstriction in asthmatic subjects [7].

Ice hockey players may be at increased risk for asthma or exercise-induced asthma because they exercise or play intensively in cold air $\left(5-10^{\circ} \mathrm{C}\right)$, albeit not as cold as for cross-country skiers. Therefore, professionally coached, elite ice hockey players were studied and compared with elite floor ball players and the general Swiss population. Clinical symptoms of asthma, lung function and bronchial hyperresponsiveness (methacholine and exercise-induced challenge) were examined.

\section{Subjects and methods}

Twenty-six elite ice hockey players (Ice Hockey Club Chur) and 24 elite floor ball players of the Swiss cham- pion floor ball team (Rot-Weiss Chur) were invited to participate in the study. All gave written, informed consent for the study, which had been approved by the local Ethical Committee. The study was carried out in August and September 1996. The ice hockey players were on average 24 (18-35) yrs old and the floor ball players 20 (17-29) yrs old. All subjects were instructed to avoid any medication, including antiasthmatic drugs, for at least $48 \mathrm{~h}$ before the study.

In order to identify subjects with a history of asthma or atopic diseases all players were asked to complete a questionnaire including 22 questions on personal history of allergy and smoking habits, which had been part of the validated SAPALDIA questionnaire [8]. Asthma was assumed to be present when positive answers were given to both of the following questions: "Have you ever had asthma?" and "Was this confirmed by your doctor?". Questionnaires were checked and discussed with each subject.

Forced expiratory volume in one second (FEV1) and vital capacity (VC) were measured in the hospital with a spirometer (SensorMedics®; Gambro AG, Switzerland). The FEV1 recorded was the best value of three measurements. In addition, slow VC measurements were undertaken and the highest values of three forced and three slow expirations were recorded [9].

Bronchial hyperresponsiveness was assessed with a methacholine challenge test, following the methodology used by the German working group on bronchial provocation test [10] with the help of a jet nebulizer (Pari Provotest ${ }^{\circledR}$; Labhardt AG, Switzerland) with an output of 5.0 
$\mathrm{L} \cdot \mathrm{min}^{-1}$. The jet nebulizer generates droplets with a median mass aerodynamic diameter of $3.6 \mu \mathrm{m}$ and $65 \%$ of the droplets are $<5 \mu \mathrm{m}$. Each of the increasing doses of methacholine (100, 200, 400, 500 and $1000 \mu \mathrm{g})$ was inhaled from a reservoir bag containing the given dose of methacholine within 5-10 L of air at a respiratory rate of 15 breaths. $\mathrm{min}^{-1}$ during $1 \mathrm{~min}$. Measurements of FEV1 were performed with a spirometer, beginning $1 \mathrm{~min}$ after inhalation. The interval between each dose was $2 \mathrm{~min}$. The dose of methacholine that produced a $20 \%$ decrease in FEV1 (PD20) [11, 12]. The challenge test was regarded as positive when PD20 was $<2 \mathrm{mg}$, which represents an arbitrary cut-off point close to that of $1.5 \mathrm{mg}(7.8 \mu \mathrm{mol})$ used by YAN et al. [13]. PD20 was logarithmically analysed as geometric mean values. A dose-response slope was calculated for all subjects as the percentage fall in FEV1 at last dose divided by the total dose administered [14].

The exercise challenge was an $8 \mathrm{~min}$, standardized, free-running or free-skating test in either the gymnastics hall (floor ball players) or the ice hall (ice hockey players) [15]. All subjects had to reach $>80 \%$ of their predicted maximal cardiac frequency $\left(f_{\mathrm{C}}>160\right.$ beats.min $\left.{ }^{-1}\right)$. Spirometry was performed with four portable spirometers (Spirovit SP-1®, Schiller AG, Switzerland), which were calibrated before each session with a $2 \mathrm{~L}$ air syringe. The spirometric measurements were made before running or skating and 0,5,10,20 and 30 min after the exercise test, respectively. For the purpose of the study, exercise-induced bronchospasm (EIB) was defined as a fall Š10\% in FEV1 compared with pre-exercise values $[12,15,16]$. Subjects were asked about their symptoms after the run, which included chest tightness, difficulty in breathing and/or squeaky or whistling chest.

Asthma was defined as bronchial hyperresponsiveness plus positive answers to the two cardinal questions of the questionnaire (see above).

Table 1. - Methacholine provocation test

\begin{tabular}{|c|c|c|c|}
\hline & $\begin{array}{l}\text { Floor ball } \\
\text { players }\end{array}$ & $\begin{array}{l}\text { Ice hockey } \\
\text { players }\end{array}$ & p-value \\
\hline $\begin{array}{l}\text { Positive challenge } \\
\text { test } \mathrm{PD} 20<2 \mathrm{mg}\end{array}$ & $5(20.8 \%)$ & $9(34.6 \%)$ & $<0.05$ \\
\hline$\Delta \% \mathrm{FEV}_{1}$ & $75 \pm 1$ & $69 \pm 10$ & NS \\
\hline PD20 mg*t & $1.64 \pm 0.40$ & $0.52 \pm 0.33$ & 0.001 \\
\hline $\begin{array}{l}\text { Dose-response slope } \\
\% \cdot \mathrm{mg}^{-1} \frac{1}{*}\end{array}$ & $47.8 \pm 14.5$ & $557 \pm 1147$ & NS \\
\hline
\end{tabular}

Values are means \pm SD. PD20: provocative dose causing a $20 \%$ fall in the forced expiratory volume in one second (FEV1). *: methacholine dose at which FEV1 decreased by $20 \%$; five and nine subjects, respectively. : geometric mean. in FEV1 at the last dose divided by the total dose administered. Ns: nonsignificant.
For statistical analysis, StatView 4.0 software (Abacus Inc, Berkeley, CA, USA) was used on an Apple Macintosh SE/30. Besides descriptive statistics, Pearson's chi-squared test was used for the comparison between groups and one-way analysis of variance (ANOVA) for two-category data with Fisher's t-test for significance. All p-values were two tailed and $p<0.05$ was interpretated as statistically significant.

\section{Results}

There was no significant difference in the prevalence of atopy measured by questionnaire. Both teams had 10 players with atopy $(42 \%$ in ice hockey players and $38 \%$ in floor ball players).

No significant difference was observed in the lung function with regard to $\mathrm{VC}$ and FEV1 between ice hockey and floor ball players. Percentage predicted $( \pm \mathrm{SD})$ for $\mathrm{VC}$ in the ice hockey players and floor ball players was $108( \pm 9)$ and $106( \pm 13)$, respectively, and for FEV1 was $107( \pm 10)$ and $102( \pm 11)$, respectively.

Data on bronchial hyperresponsiveness are given in table 1. Ice hockey players had an increased bronchial hyperresponsiveness compared with floor ball players and the general Swiss population (SAPALDIA). Nine of the 26 ice hockey players $(34.6 \%)$ and five of the 24 floor ball players $(20.8 \%)$ showed a positive methacholine challenge test $(\mathrm{p}<0.05)$. The PD20 was significantly lower in ice hockey players than in floor ball players (geometric mean values $0.52 \mathrm{mg}$ versus $1.64 \mathrm{mg}$; $\mathrm{p}=0.001$ ), but there was no significant difference in the dose-response slopes.

Asthma, as defined by the study criteria, tended to be more prevalent in ice hockey players than in floor ball players (absolute values: 5/26 and 1/24, respectively, not significant (Ns); relative values: $19.2 \%$ and $4.1 \%$, $\mathrm{p}<0.05$ ). Physician-diagnosed asthma was reported by five of the 26 ice hockey players and by three of the 24 floor ball players. One of the five ice hockey players and two of the three floor ball players had no bronchial hyperresponsiveness and thus did not have asthma by our criteria (table 2). Four of the five asthmatic ice hockey players were taking salbutamol regularly, compared with none of the floor ball players. No players in either team inhaled steroids regularly. Bronchial hyperresponsiveness without airway symptoms (wheezing, breathlessness and chest tightness) was observed in four ice hockey players and in four floor ball players.

An EIB was found following the $8 \mathrm{~min}$, standardized, free-running or free-skating challenge in three of the 26 ice hockey players and in one of the 24 floor ball players

Table 2. - Prevalence and characteristics of asthma

\begin{tabular}{lllc}
\hline & $\begin{array}{c}\text { Floor ball } \\
\text { players } \\
\mathrm{n}(\%)\end{array}$ & $\begin{array}{c}\text { Ice hockey } \\
\text { players } \\
\mathrm{n}(\%)\end{array}$ & $\mathrm{p}$-value \\
\hline $\begin{array}{l}\text { Asthma bronchiale } \\
\text { Physician-diagnosed asthma }\end{array}$ & $1(4)$ & $5(19)$ & $<0.05$ \\
$\quad$ with bronchial hyperresponsiveness & $1(4)$ & $4(15)$ & $\mathrm{NS}$ \\
$\quad$ without bronchial hyperresponsiveness & $2(8)$ & $1(4)$ & $\mathrm{NS}$ \\
Regular inhalation of $\beta_{2}$-agonists & 0 & $4(15)$ & $\mathrm{NS}$ \\
Regular inhalation of steroids & 0 & 0 & $\mathrm{~N}$ \\
\hline
\end{tabular}

Ns: nonsignificant. 
(Ns). The three ice hockey players as well as the one floor ball player who suffered an exercise-induced bronchospasm also complained of chest tightness or a squeaky or whistling chest. Three of the 26 ice hockey players and none of the floor ball players were smokers. None of the asthmatics were smokers.

\section{Discussion}

This study shows that bronchial hyperresponsiveness, asthma and exercise-induced asthma occur more frequently in ice hockey players than in floor ball players. Whereas the data of the floor ball players were similar to those found in the general Swiss population [3], ice hockey players had a 1.7-fold increased incidence of bronchial hyperresponsiveness to methacholine compared with floor ball players, a 4.6-fold increase in asthma and a 2.7-fold increase in exercise-induced asthma.

A greater proportion of subjects with increased bronchial hyperresponsiveness to methacholine were ice hockey players and their PD20 was significantly lower than in floor ball players, but there was no significant difference in the dose-response slopes. Therefore, the results suggest that the severity of bronchial hyperresponsiveness was increased in ice hockey players compared with floor ball players, but the study was limited by the small sample size and the relatively low doses of methacholine used in the bronchial challenge.

It is very likely that cold air caused the increased prevalence of asthma and bronchial hyperresponsiveness in ice hockey players. Although selection bias cannot be excluded completely, it seems rather unlikely, for instance, that for an unknown reason individuals hyperreactive to methacholine tend to choose ice hockey rather than floor ball and vice versa. Swiss elite athletes, in general, have a $4.25 \%$ prevalence of exercise-induced asthma [4], which is less than the $11.2 \%$ seen in American athletes during the 1984 Summer Olympic Games [17]. However, asthma was found in 13 of 47 Swedish elite cross-country skiers (31\%) [5] and exercise-induced asthma in 43 of 124 professionally coached American figure skaters (35\%) [18]. Strenuous exercise under outdoor subzero winter conditions caused an abnormal bronchospasm in a high proportion of elite runners who were atopic [19]. Ice hockey players exercise and play intensively in cold air $\left(5-10^{\circ} \mathrm{C}\right)$, which is, however, not as cold as during outdoor activities. This could be an explanation for the even higher prevalence of asthma and bronchial hyperresponsiveness in cross-country skiers [5].

The difference in the hyperresponsiveness to exercise and methacholine is surprising. It could be explained by the difference in the timing of the challenge. Floor ball players underwent the exercise challenge before usual training, whereas we were unable to perform the exercise challenge in the ice hockey players until after training. The methacholine challenge was performed on a day when no training was undertaken in both groups. Previous studies have shown a lower sensitivity to hyperventilation of cold air in children [20] as well as in adults [21], compared with pharmacological challenge tests such as methacholine or histamine. Asthma is characterized by an excessive inflammatory reaction in response to antigenic, as well as, nonantigenic stimuli, i.e. exercise or voluntary hyperpnoea in cold, dry air. The antigenic and nonantigenic responses have different pathophysiological mechanisms and are synergistic [22].

The acute effect of exposure to cold, dry air on human airway responsiveness is only poorly understood. It has been suggested that dry air damages the bronchial mucosa and this could contribute to a higher bronchial responsiveness [23].

Astoundingly, only $26 \%$ of these above-mentioned world-class athletes, who suffered from exercise-induced asthma in the 1984 Summer Olympic Games, had a previous history of asthma [17]. Also, one of the five ice hockey players did not know that he had asthma. The signs and symptoms of bronchospasm are often subtle and athletes are frequently unaware of any pulmonary disease. A sensation of shortness of breath, chest tightness, coughing, chest discomfort or pain may be all that is experienced [24, 25] and may be misinterpreted as insufficient fitness. Most of the ice hockey players and few of the floor ball players coughed at the end of the exercise challenge, but all of the three ice hockey players, as well as the one of the floor ball players who suffered on an exerciseinduced bronchospasm, also complained about chest tightness or squeaky or whistling chest. It is likely that many athletes at all levels of competition suffer from unrecognized asthma and exercise-induced asthma [24]. Coaches, trainers and team physicians should be made aware of the diversity of symptoms and should look for asthma as part of the screening process so that athletes receive appropriate treatment $[26,27]$.

Four of the 25 ice hockey players used antiasthmatic drugs (Salbutamol, on an irregular basis), whereas none of the floor ball players used drugs. No asthmatic players were treated with inhaled corticosteroids. A Dutch trial with long-term therapy with inhaled budesonide in 55 children with exercise-induced asthma showed a reduction in the incidence of exercise-induced asthma by $33 \%$ and a reduction in the severity by $50 \%$ [28]. Asthma and exercise-induced asthma are not only underdiagnosed but also undertreated. Performance may be limited by asthma or exercise-induced asthma. With effective screening programmes athletes could be treated early in life and participate more fully in their sports.

\footnotetext{
Acknowledgements: The authors thank M. Maag for her expert technical help, W. Brunner and S. Downs for the revision of the manuscript and Schiller AG, Switzerland, for the portable spirometers.
}

\section{References}

1. Roberts JA. Exercise-induced asthma in athletes. Sports Med 1988; 6: 193-196.

2. Leuenberger $\mathrm{Ph}$, Künzli $\mathrm{N}$, Ackermann-Liebrich $\mathrm{U}$, et al. and the SAPALDIA-Team. Etude suisse sur la pollution de l'air et les maladies respiratoires chez l'adulte. Schweiz Med Wschr 1998; 128: 150-161.

3. Wüthrich B, Schindler C, Leuenberger Ph, AckermannLiebrich $U$ and the SAPALDIA-Team. Prevalence of atopy and pollinosis in the adult population of Switzerland (SAPALDIA study). Int Arch Allergy Immunol 1995; 106: 149-156.

4. Kaelin M, Brändli O. Anstrengungsasthma bei Schweizer Spitzensportlern. Schweiz, Med Wschr 1993; 123: 174-182. 
5. Larsson K, Ohlsén P, Larsson L, et al. High prevalence of asthma in cross country skiers. BMJ 1993; 307: 13261329.

6. Anderson SD, Schoeffell RE, Black JL, et al. Airway cooling as a stimulus to exercise induced asthma: a reevaluation. Eur J Respir Dis 1985; 67: 20-25.

7. Deal EC, McFadden ER, Ingram RH, Breslin FJ, Jaeger JJ. Airway responsiveness to cold air and hyperpnea in normal subjects and in those with hay fever and asthma. Am Rev Respir Dis 1980; 121: 621-628.

8. Strauss RH, McFadden ER, Ingram RH, et al. Enhancement of exercise induced asthma by cold air. $N$ Engl $J$ Med 1977; 297: 734-747.

9. Künzli N, Ackermann-Liebrich U, Keller R, et al. Variability of FVC and FEV1 due to technician, team, device, and subject in an eight centre study: three quality control studies in SAPALDIA. Eur Respir J 1995; 8: 371-376.

10. Deutsche Gesellschaft für Pneumologie - Wissenschaftliche Arbeitsgruppe "Bronchiale Provokationstests". Empfehlungen zur Durchführung bronchialer Provokationstests mit pharmakologischen Substanzen. Medizinische Klinik 1997; 92: 458-463.

11. Burrows B, Niden A, Barclay W, et al. Chronic obstructive lung disease: II. Relationship of clinical and physiologic findings to severity of airway obstruction. Am Rev Respir Dis 1965; 91: 665-678.

12. Pratter MR, Irwin RS. The clinical value of pharmacologic bronchoprovocation challenge. Chest 1984; 85: 260265.

13. Yan K, Salome C, Woolcock AJ. Rapid method for measurement of bronchial responsiveness. Thorax 1983; 38: $55-61$.

14. O'Connor G, Sparrow D, Taylor D, et al. Analysis of doseresponse curves to methacholine. Am Rev Respir Dis 1987; 136: $1412-1417$.

15. Eliasson AH, Phillips YY, Rajagopal R. Sensitivity and specificity of bronchial provocation testing. Chest 1992; 102: 347-355.
16. Sterk PJ, Fabbri LM, Quanjer PH, et al. Airway responsiveness. Standardized challenge testing with pharmacological, physical and sensitizing stimuli in adults. Eur Respir J 1993; 6: Suppl. 16, 53-83.

17. Voy RO. The US Olympic Committee experience with exercise-induced bronchospasm, 1984. Med Sci Sports Exerc 1986; 18: 328-330.

18. Mannix ET, Farber MO, Palange P, et al. Exercise-induced asthma in figure skaters. Chest 1996; 109: 312-315.

19. Helenius IJ, Tikkanen HO, Haahtela T. Exercise-induced bronchospasm at low temperature in elite runners. Thorax 1996; 51: 628-629.

20. Galdès-Sebaldt M, McLaughlin FJ, Levison H. Comparison of cold air, ultrasonic mist, and methacholine inhalations as test of bronchial reactivity in normal and asthmatic children. J Pediatr 1985; 107: 526-530.

21. Koskela HO, Räsänen SH, Tukiainen HO. The diagnostic value of cold air hyperventilation in adults with suspected asthma. Respir Med 1997; 91: 470-478.

22. Giesbrecht G, Younes M. Exercise- and cold-induced asthma. Can J Appl Physiol 1995; 20: 300-314.

23. Freed AN. Models and mechanisms of exercise-induced asthma (Review). Eur Respir J 1995; 8: 1770-1785.

24. Kobayashi RH, Mellion MB, Kobayashi ALD. What is the current status of management of the patient with exercise-induced asthma? Nebr Med J 1994; 79: 189-194

25. Smith SB. Exercise-induced asthma: diagnostic clues with recommendations for treatment. Postgrad Med 1985; 77 : $42-45$.

26. Nastasi KJ, Heinly TL, Blaiss MS. Exercise-induced asthma and the athlete. J Asthma 1995; 32: 249-257.

27. Mellion MB, Kobayashi RH. Exercise-induced asthma. Am Family Physician 1992; 45: 2671-2677.

28. Waalkens HJ, van Essen-Zandvliet EE, Gerritsen J, et al. The effect of an inhaled corticosteroid (budesonide) on exercise-induced asthma in children. Eur Respir J 1993; 6: 652-656. 